\title{
Formación, Motivación y Condiciones Laborales de los Docentes de Primaria en Perú
}

\section{F. Javier Murillo}

Facultad de Formación de Profesorado y Educación, Universidad Autónoma de Madrid, España.

\section{Marcela Román}

Centro de Investigación y Desarrollo de la Educación (CIDE), Universidad Alberto Hurtado, Chile. 


\section{Resumen}

En este artículo, se estudió la situación de los docentes de primaria en Perú en el contexto de América Latina. Para ello, se hace una explotación especial de los datos del Serce focalizado en cinco elementos: características de los docentes, formación, condiciones laborales, distribución de su tiempo y, finalmente, satisfacción. Entre los resultados, sobresalen dos elementos. Por un lado, el Perú es el país cuyos docentes están más insatisfechos con su trabajo, y en mayor proporción les gustaría cambiar de escuela. Por otro, son sus docentes quienes más proporción de tiempo dedican a la docencia directa en el aula y, con ello menos a planificar y preparar clases, corregir, reunirse con sus colegas, entre otros. Por su parte, la evidencia respecto de características, formación, condiciones laborales, señala que ellos se encuentran en una situación promedio en la región. Todo ello lleva a concluir que es necesario que las autoridades educativas y la sociedad en su conjunto confíen más en los docentes y su profesionalidad.

Palabras clave: Docentes, Educación Primaria, Perú, satisfacción del docente, formación docente

\section{Abstract}

In the current article, we study the state of Peruvian primary teachers in the context of Latin America utilizing data from the Second Regional Comparative and Explicative Study. We focus on five aspects: Social characteristics of teachers, their professional formation, working conditions, time management, and job satisfaction. The data analysis highlights two main aspects of teaching in Peru. First, it's observed that Peruvian teachers are among the most dissatisfied with their jobs in Latin America, and are eager to switch jobs in order to acquire better working conditions. Second, primary teachers are the ones that dedicate more time to classroom activities, but less time to other important activities such as planning and preparing their learning sessions, reviewing students' work, or meeting with their colleagues. Also, evidence shows that Peruvian teachers' formation and working conditions are equivalent to that of their peers in the region. We conclude that educational authorities as well as Peruvian society need to develop more thrust in teachers and their professionalism.

Keywords: Teachers, Primary Education, Peru, Teacher Satisfaction, Teacher Education 
as evidencias empíricas son claras y consistentes en la defensa de que el trabajo de los profesores y profesoras en el aula es el factor escolar de mayor peso en el aprendizaje de los estudiantes (por ejemplo, Creemers, 1994; Murillo, 2005, 2007; Sammons, 2007; Román, 2008; Murillo, Martínez-Garrido y Hernández-Castilla, 2011). En otras palabras, lo que aprenden, saben y pueden llegar a ser y hacer los estudiantes dependerá en gran medida de lo que saben, piensan y hacen sus docentes. Todo ello, sin olvidar que su calidad no responde solo del profesor y su práctica, sino que esta se encuentra anclada fuertemente en el tipo de liderazgo de la dirección y condiciones del centro, al tiempo que se enmarca en las regulaciones, políticas y variables del contexto y sistema educativo en el que tal enseñanza se desarrolla. A su vez, la calidad de la educación se explica y comprende desde el docente: desde sus saberes y práctica pedagógica, pero, quizá más aun, de su actitud, motivación y expectativas hacia la educación, la escuela y sus estudiantes. Importa y preocupa, así, indagar cuáles son las particularidades o características de los actuales docentes, compararlas en función de sistemas, contextos y países, al tiempo que se analiza las condiciones laborales en las cuales se pide y espera que se desarrolle una buena enseñanza.

Una primera mirada a la situación de los docentes de América Latina nos deja un dato, más que sorprendente, preocupante: Perú es el país cuyos docentes de Educación Primaria están más descontentos con su trabajo (Gráfico 1). Este hecho impone al sistema educativo peruano importantes retos. El primero es comprender las razones de tal sensación que sin duda está afectando su práctica y, en segundo lugar -y quizás aún más importante-, apoyar a sus profesores, confiar en ellos, potenciar su profesionalidad y mejorar su autoestima. 


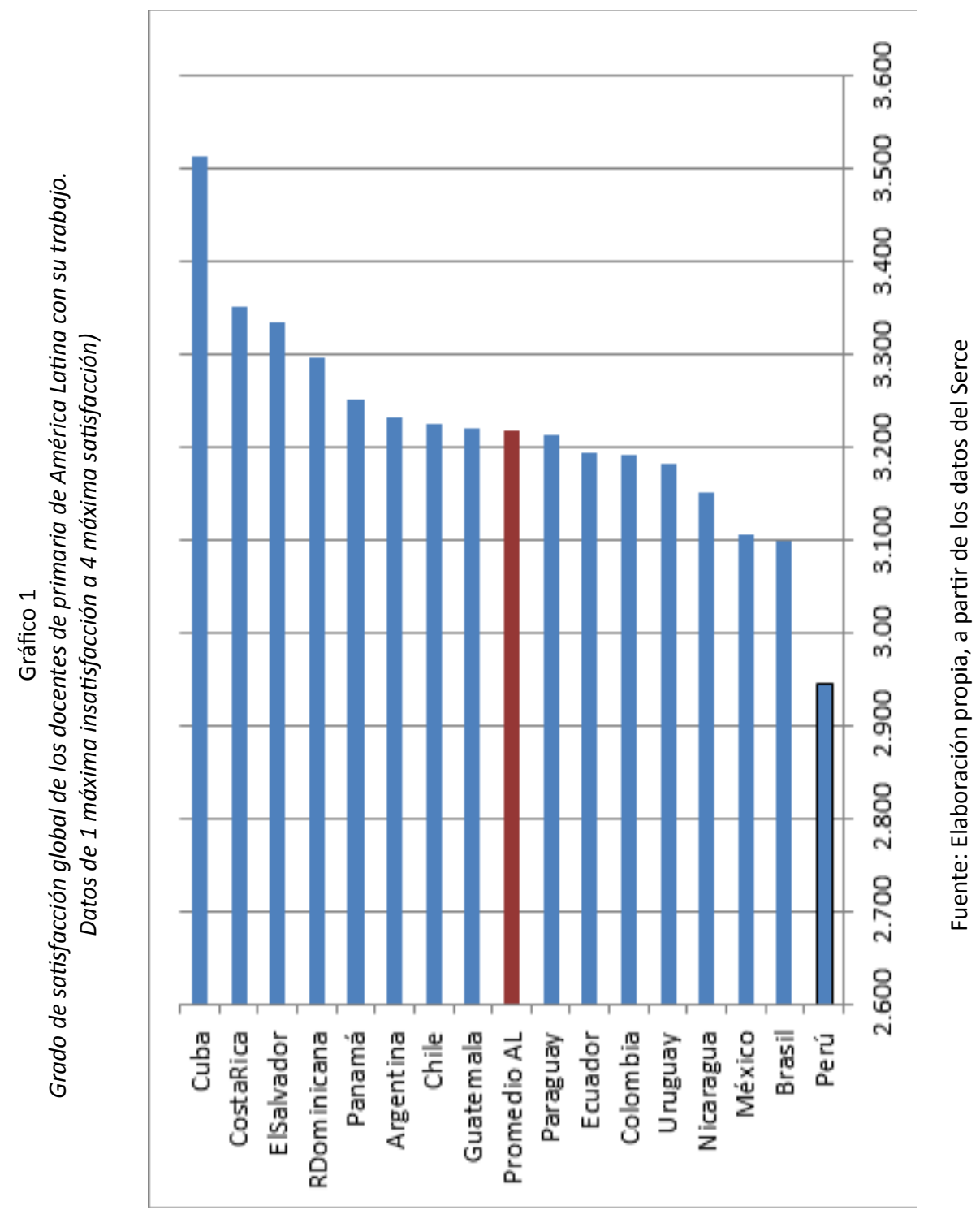


En este artículo, nos proponemos profundizar en la situación de los docentes de educación primaria visibilizar quiénes son los profesionales que están a cargo de las aulas de primaria en el Perú. Ello implica conocer sus trayectorias, condiciones en las que trabajan, así como de su motivación y satisfacción con la labor formadora, entre otros aspectos que pudieran constituirse en un interesante aporte para las acciones de política. Es decir, acciones que buscan mejorar la calidad de la educación mediante el incremento y fortalecimiento de la calidad docente.

Con tales propósitos, se realiza una explotación especial de los datos del Segundo Estudio Comparativo y Explicativo (Serce) desarrollado por el Laboratorio Latinoamericano de Evaluación de la Calidad de la Educación (Llece, 2008) de la Unesco entre 2006 y 2009. La muestra utilizada para esta investigación estuvo conformada por 4361 docentes de sexto de educación primaria de 16 países de América Latina; 266 maestros eran peruanos. Los datos se recogieron mediante un cuestionario dirigido a profesores y profesoras, compuesto de una batería de preguntas cerradas que recabó información sobre su formación inicial, organización y condiciones del trabajo que realizan. También, se pudo observar sus percepciones y actitudes respecto de diferentes aspectos de la enseñanza y de la escuela donde desempeñan su labor.

El artículo está organizado en cinco partes, a saber: características de los docentes, formación, condiciones laborales, distribución de su tiempo, y satisfacción. A estas se añade una última parte en la que se discuten los resultados y se aborda alguna de las implicaciones de los mismos para el desarrollo de políticas.

\section{Características de los docentes}

El Perú es uno de los países de América Latina con menor cantidad de mujeres enseñando en Educación Primaria. Efectivamente, frente a un $70,3 \%$ de mujeres como promedio para los países de la Región, las profesoras en Perú representan el 60,4\% del total para ese nivel. Esta es una situación análoga a Guatemala, México y Colombia, que son los países que presentan el menor porcentaje de docentes mujeres; en oposición a lo que ocurre en Argentina, Brasil, y Nicaragua, donde más del $75 \%$ de los docentes de primaria son mujeres (Tabla 1).

Con importantes diferencias según países, las mujeres representan un porcentaje mayor del total de educadores en el ámbito urbano, que en el rural. En el caso de México, por ejemplo, las profesoras mujeres representan cerca de un tercio $(33,8 \%)$ de los docentes de primaria en escuelas rurales. 
En el otro extremo, se encuentra Argentina, donde el 75,4\% de los maestros rurales son mujeres.

La mayor proporción de docentes mujeres en el Perú se encuentra en las escuelas urbanas de administración privada, en donde alcanzan el 76,3\% del total. En las escuelas urbanas públicas, este porcentaje es del $60,7 \%$, cifra que disminuye a un $47,4 \%$, para las escuelas rurales (Tabla 1 ).

Tabla 1

Porcentaje de mujeres docentes de primaria en América Latina (total y por tipo de escuela)

\begin{tabular}{lcccc}
\hline & Total & Público/ Urbano & Privado/ Urbano & Rural \\
\hline Argentina & 88,38 & 90,79 & 90,83 & 75,38 \\
Brasil & 75,81 & 77,07 & 75,90 & 69,23 \\
Colombia & 59,85 & 57,69 & 61,61 & 61,86 \\
Costa Rica & 79,29 & 86,49 & 88,89 & 68,42 \\
Cuba & 64,37 & 64,71 & & 63,29 \\
Chile & 68,61 & 71,24 & 72,28 & 54,55 \\
Ecuador & 56,94 & 50,00 & 77,50 & 54,43 \\
El Salvador & 68,85 & 73,60 & 55,17 & 66,98 \\
Guatemala & 53,81 & 58,33 & 77,42 & 43,12 \\
México & 52,61 & 57,80 & 77,42 & 33,80 \\
Nicaragua & 82,63 & 85,82 & 92,50 & 69,35 \\
Panamá & 70,80 & 69,67 & 86,49 & 65,93 \\
Paraguay & 71,66 & 79,79 & 100,00 & 58,20 \\
\hline Perú & 60,40 & 60,71 & 73,58 & 47,37 \\
\hline Rep. Dominicana & 81,25 & 77,94 & 93,33 & 78,26 \\
Uruguay & 90,24 & 92,31 & 93,75 & 79,63 \\
\hline Promedio & 70,34 & 72,12 & 76,04 & 61,86 \\
\hline
\end{tabular}

Fuente: Elaboración propia, a partir de los datos del Serce

La edad promedio de los docentes peruanos es de 41,1 años, lo que supone uno de los cuerpos docentes más envejecidos de toda la región. A pesar de ello, puede considerarse como una población joven de promedio. De esta forma, llama la atención la juventud de los docentes de primaria en casi todos los países de América Latina. Tampoco, se vislumbra grandes diferencias según el tipo de escuela y su ubicación (rural o urbana). Así, la edad promedio de quienes enseñan en escuelas primarias de América Latina, es de 39,9 años. Esta cifra es un poco mayor $(41,6)$ entre quienes lo hacen en escuelas 
públicas urbanas (Tabla 2). A su vez, la edad promedio entre los docentes de Perú es mayor entre quienes desempeñan sus funciones en escuelas públicas de contextos urbanos (43,1 años). El promedio menor en dicho país se encuentra entre quienes enseñan en escuelas de gestión privada, ubicadas en contexto urbano (35,1 años). Paraguay y Guatemala muestran un promedio de edad bastante menor con 34,7 años y 35,8 respectivamente. Por su parte, Chile es el país con mayor edad promedio entre sus docentes de primaria (45,8 años).

Tabla 2

Edad promedio de los docentes de escuelas de Primaria en América Latina (total y por tipo de escuela)

\begin{tabular}{lcccc}
\hline & Total & Público/ Urbano & Privado/ Urbano & Rural \\
\hline Argentina & 40,84 & 42,47 & 37,69 & 40,11 \\
Brasil & 37,86 & 38,16 & 37,36 & 37,17 \\
Colombia & 39,99 & 43,29 & 36,82 & 37,35 \\
Costa Rica & 40,63 & 40,96 & 42,00 & 39,94 \\
Cuba & 40,75 & 40,16 &. & 42,65 \\
Chile & 45,81 & 48,28 & 41,83 & 46,26 \\
Ecuador & 42,70 & 47,20 & 37,63 & 40,14 \\
El Salvador & 38,74 & 41,08 & 36,72 & 36,54 \\
Guatemala & 35,84 & 40,72 & 31,20 & 32,86 \\
México & 40,76 & 41,89 & 41,27 & 38,82 \\
Nicaragua & 37,72 & 40,01 & 38,34 & 32,44 \\
Panamá & 40,07 & 41,18 & 45,73 & 36,31 \\
Paraguay & 34,69 & 35,28 & 35,32 & 34,07 \\
\hline Perú & 41,08 & 43,06 & 35,31 & 41,53 \\
\hline Rep. Dominicana & 38,04 & 40,54 & 32,96 & 37,48 \\
Uruguay & 42,19 & 41,30 & 46,56 & 41,50 \\
\hline Promedio & 39,86 & 41,60 & 38,45 & 38,45 \\
\hline
\end{tabular}

Fuente: Elaboración propia, a partir de los datos del Serce

Analizado por tramos de edad, se observa que la gran mayoría de los docentes peruanos está en un tramo de edad "intermedio" (el 73\% tiene entre 29 y 48 años de edad). Hay muy pocos con más de 58 años (solo el 1,6\%) y pocos con menos de 28 años $(6,4 \%)$. Por lo tanto, ni se prevén casos derivados de la jubilación de docentes ni tampoco de su excesiva juventud. 
Tabla 3

Distribución de los docentes de Primaria de América Latina en función de su edad

\begin{tabular}{lccccc}
\hline & $19-28$ & $29-38$ & $39-48$ & $49-58$ & 59 o más \\
\hline Argentina & 10,72 & 30,42 & 37,91 & 15,71 & 5,24 \\
Brasil & 18,18 & 38,38 & 26,77 & 14,90 & 1,77 \\
Colombia & 10,65 & 38,96 & 26,49 & 22,08 & 1,82 \\
Costa Rica & 6,57 & 29,93 & 48,18 & 14,60 & 0,73 \\
Cuba & 11,08 & 32,63 & 31,44 & 23,05 & 1,80 \\
Chile & 9,51 & 17,05 & 26,56 & 36,07 & 10,82 \\
Ecuador & 9,57 & 30,14 & 25,36 & 29,67 & 5,26 \\
El Salvador & 10,38 & 38,85 & 39,62 & 9,23 & 1,92 \\
Guatemala & 29,91 & 28,63 & 29,06 & 11,54 & 0,86 \\
México & 11,00 & 22,49 & 51,20 & 14,35 & 0,96 \\
Nicaragua & 22,88 & 27,97 & 34,32 & 14,41 & 0,42 \\
Panamá & 12,96 & 35,63 & 21,46 & 28,34 & 1,62 \\
Paraguay & 23,67 & 49,39 & 22,04 & 3,27 & 1,63 \\
\hline Perú & 6,45 & 33,06 & 39,92 & 18,95 & 1,61 \\
\hline Rep. Dominicana & 15,60 & 38,30 & 34,75 & 11,35 & 0,00 \\
Uruguay & 12,16 & 23,99 & 33,11 & 26,69 & 4,05 \\
\hline Promedio & 13,83 & 32,24 & 33,01 & 18,39 & 2,53 \\
\hline
\end{tabular}

Fuente: Elaboración propia a partir de los datos del Serce

Estos datos se confirman mediante el análisis de su experiencia docente. Para el conjunto de América Latina, los docentes tienen cerca de 16 años de experiencia docente como promedio. Respecto a la antigüedad como profesor en la escuela donde laboran, llega a los 8,3 años. Esta estabilidad es, en promedio, un año mayor entre quienes trabajan en escuelas públicas urbanas (9,4 años). Claramente, la experiencia está relacionada con la edad promedio de los maestros; esta es mayor entre quienes exhiben también una mayor edad promedio. En Chile, por ejemplo, los profesores exhiben el promedio mayor en cuanto a experiencia docente (21,1 años) y son, también, los de mayor edad promedio. Caso inverso ocurre con Paraguay y Guatemala, países con las menores cifras de experiencia docente y con el promedio de edad menor entre sus profesores. En el caso del Perú, la experiencia docente promedio es de 15,1 años; mientras que la antigüedad o estabilidad en el cargo actual llega a 8 años. Estas cifras son mayores en los profesores de escuelas urbanas públicas ( 9,3 años) y mucho menores para quienes lo hacen 14 I en escuelas privadas (5,2 años). Esto se puede observar en la siguiente Tabla. 
Tabla 4

Años de experiencia docente y de antigüedad en la escuela de los docentes de primaria en América Latina (total y por tipo de escuela)

\begin{tabular}{lcccccccc}
\hline & \multicolumn{3}{c}{ Experiencia como docente } & \multicolumn{3}{c}{ Antigüedad en ese centro } \\
\cline { 2 - 9 } & \multicolumn{3}{c}{ Público/ } & Privado/ & \multicolumn{3}{c}{ Público/ } & Privado/ \\
Trbano & Urbano & Rural & Total & Urbano & Urbano & Rural \\
\hline Argentina & 14,86 & 16,06 & 12,80 & 13,88 & 8,79 & 8,50 & 9,51 & 8,65 \\
Brasil & 13,95 & 13,54 & 15,07 & 14,31 & 6,70 & 6,68 & 6,83 & 6,60 \\
Colombia & 15,10 & 19,27 & 11,40 & 11,51 & 7,40 & 9,24 & 5,67 & 5,82 \\
Costa Rica & 14,43 & 13,31 & 18,33 & 15,30 & 7,16 & 7,55 & 6,11 & 6,82 \\
Cuba & 20,06 & 19,31 &. & 22,49 & 8,77 & 8,32 &. & 10,25 \\
Chile & 21,05 & 24,31 & 15,59 & 22,16 & 12,62 & 15,00 & 9,05 & 12,76 \\
Ecuador & 18,53 & 23,97 & 13,65 & 14,80 & 11,34 & 13,46 & 8,50 & 10,38 \\
El Salvador & 13,31 & 16,40 & 11,21 & 10,25 & 7,35 & 9,19 & 4,31 & 6,00 \\
Guatemala & 11,85 & 16,48 & 9,71 & 8,34 & 6,77 & 9,33 & 5,90 & 4,74 \\
México & 18,59 & 20,03 & 18,58 & 16,44 & 7,77 & 9,09 & 6,65 & 6,27 \\
Nicaragua & 16,14 & 18,24 & 17,31 & 10,58 & 11,21 & 13,17 & 10,94 & 6,42 \\
Panamá & 15,67 & 17,08 & 21,65 & 11,30 & 8,00 & 8,00 & 12,86 & 6,01 \\
Paraguay & 10,72 & 11,45 & 11,10 & 10,04 & 8,21 & 8,63 & 8,90 & 7,69 \\
\hline Perú & 15,11 & 17,11 & 11,13 & 13,77 & 8,00 & 9,34 & 5,24 & 7,21 \\
\hline Rep. & 12,22 & 14,49 & 9,10 & 10,85 & 7,34 & 7,97 & 5,67 & 7,48 \\
Dominicana & & & & & & & & \\
Uruguay & 17,93 & 16,78 & 23,58 & 17,02 & 7,43 & 6,93 & 11,04 & 5,85 \\
\hline Promedio & 15,59 & 17,37 & 14,68 & 13,94 & 8,43 & 9,40 & 7,81 & 7,44 \\
\hline
\end{tabular}

Fuente: Elaboración propia, a partir de los datos del Serce

No parece, por tanto, que la explicación a esa insatisfacción se deba a sus características personales, dado que se encuentran en una situación intermedia respecto a su entorno. Analicemos si su formación aporta algunas luces al respecto.

\section{Formación de los docentes}

El 89,7\% de los profesores peruanos de educación primaria tiene formación inicial como docentes. Aunque estos datos suponen la existencia de un 10\% que no lo tiene, también, indican que este es uno de los países de América Latina con un menor porcentaje de docentes sin la formación inicial adecua- 
da. Efectivamente, solo Paraguay y Uruguay tienen un mayor porcentaje de profesores con estudios de formación inicial como docente que Perú (91,2\% y $99,7 \%)$, lo que da muestra de que están en una buena situación, al menos en términos relativos.

El análisis en función del tipo de escuela muestra que, en Perú -como en casi todos los países-, se incrementa el porcentaje de docentes sin formación inicial completa en las escuelas rurales. Ello se aprecia en la Tabla 5 con las cifras de quienes exhiben una formación inicial completa por tipo de escuela donde enseñan.

De aquí, puede derivarse que, al menos en la formalidad, la gran mayoría de los docentes peruanos se encuentra adecuadamente formada en una cifra superior a la del resto de América Latina.

Tabla 5

Porcentaje de docentes de primaria en América Latina con estudios de formación docente finalizados (total y por tipo de escuela)

\begin{tabular}{lcccc}
\hline & Total & Público/ Urbano & Privado/ Urbano & Rural \\
\hline Argentina & 88,28 & 88,53 & 89,42 & 85,48 \\
Brasil & 78,43 & 77,31 & 84,15 & 75,00 \\
Colombia & 86,67 & 88,46 & 83,93 & 86,46 \\
Costa Rica & 86,96 & 93,15 & 87,50 & 78,95 \\
Cuba & 73,87 & 75,20 & & 69,62 \\
Chile & 88,78 & 93,96 & 81,00 & 88,89 \\
Ecuador & 77,45 & 86,21 & 69,23 & 71,79 \\
El Salvador & 85,16 & 88,71 & 78,57 & 82,69 \\
Guatemala & 27,73 & 37,08 & 33,33 & 17,82 \\
México & 65,20 & 69,52 & 80,65 & 51,47 \\
Nicaragua & 87,12 & 93,18 & 84,62 & 75,81 \\
Panamá & 75,30 & 74,17 & 75,68 & 76,67 \\
Paraguay & 91,16 & 94,79 & 96,77 & 86,89 \\
\hline Perú & 89,71 & 91,91 & 88,00 & 85,96 \\
\hline Rep. Dominicana & 71,53 & 73,53 & 63,33 & 73,91 \\
Uruguay & 99,66 & 99,48 & 100,00 & 100,00 \\
\hline Promedio & 79,56 & 82,82 & 79,75 & 75,46 \\
\hline
\end{tabular}

Fuente: Elaboración propia, a partir de los datos del Serce

Respecto a la escolaridad máxima de los profesores y profesoras, se observan cosas interesantes. Un $5,7 \%$ de los docentes de primaria cuenta con 
estudios de postgrado en el Perú; mientras que un $36,9 \%$ de ellos posee estudios de nivel universitario y un $49,1 \%$ tiene estudios pedagógicos no universitarios. Importante es el dato que muestra que un $7,4 \%$ de los actuales maestros de primaria en el Perú solo cuenta con estudios de nivel secundario.

Estas cifras muestran una formación inferior a la de otros países. Efectivamente, si se observa los docentes con estudios de postgrado en naciones como Colombia, Brasil o El Salvador, más del 35\% de los docentes tienen esta formación ( $36,5 \%, 40,5 \%$ y $51,9 \%$, respectivamente). Si se compara entre quienes tienen secundaria o un grado menor como titulación máxima, Perú es de los países con mayor porcentaje de docentes en esta situación: un $8,2 \%$, solo superado por Guatemala, Panamá, Ecuador y Paraguay.

Tabla 6

Formación inicial de los docentes de primaria en América Latina. Distribución en función del grado máximo de estudios obtenido

\begin{tabular}{|c|c|c|c|c|c|c|}
\hline & Primaria & Secundaria & $\begin{array}{c}\text { Grado } \\
\text { técnico no } \\
\text { universitaria }\end{array}$ & $\begin{array}{l}\text { Pedagógica } \\
\text { (no universi- } \\
\text { taria) }\end{array}$ & $\begin{array}{l}\text { Universi- } \\
\text { taria }\end{array}$ & Posgrado \\
\hline Argentina & 2,36 & 5,50 & 77,23 & 0,00 & 11,52 & 2,36 \\
\hline Brasil & 1,29 & 0,77 & 0,52 & 3,35 & 52,58 & 40,46 \\
\hline Colombia & 0,00 & 2,06 & 0,00 & 5,40 & 56,04 & 36,50 \\
\hline Costa Rica & 0,71 & 0,00 & 0,00 & 0,71 & 90,00 & 7,86 \\
\hline Cuba & 0,91 & 2,74 & 1,52 & 13,68 & 68,09 & 13,07 \\
\hline Chile & 4,45 & 0,00 & 0,68 & 6,85 & 70,89 & 14,38 \\
\hline Ecuador & 1,46 & 9,76 & 1,95 & 22,93 & 61,46 & 2,44 \\
\hline El Salvador & 1,15 & 3,08 & 4,62 & 0,77 & 3,46 & 51,92 \\
\hline Guatemala & 19,03 & 35,84 & 11,50 & 19,03 & 9,73 & 0,00 \\
\hline México & 0,00 & 2,40 & 0,00 & 33,65 & 61,06 & 2,88 \\
\hline Nicaragua & 1,79 & 5,80 & 0,89 & 64,29 & 23,66 & 2,68 \\
\hline Panamá & 2,07 & 11,57 & 0,83 & 11,57 & 68,18 & 4,55 \\
\hline Paraguay & 4,56 & 4,56 & 6,22 & 60,58 & 15,35 & 0,41 \\
\hline Perú & 0,82 & 7,38 & 0,00 & 49,18 & 36,89 & 5,74 \\
\hline $\begin{array}{l}\text { Rep. } \\
\text { Dominicana }\end{array}$ & 2,88 & 2,88 & 5,76 & 3,60 & 82,01 & 2,16 \\
\hline Uruguay & 0,00 & 0,35 & 0,35 & 0,00 & 95,79 & 3,51 \\
\hline Promedio & 2,72 & 5,92 & 7,00 & 18,47 & 50,42 & 11,93 \\
\hline
\end{tabular}

Fuente: Elaboración propia, a partir de los datos del Serce 
Con todo, resulta necesario fortalecer y mejorar la formación de los docentes peruanos, situación que se constituye en un reto a afrontar por las autoridades. Ello se realizará abriendo más oportunidades para que los profesores puedan acceder a espacios de actualización y especialización de postgrado, al tiempo que se regula los requerimientos para enseñar en las escuelas del país. Difícilmente, estas brechas de formación son explicativas de su descontento o insatisfacción profesional. Recorramos, entonces, qué sucede con la situación laboral de estos docentes.

\section{Situación laboral}

Interesante resulta conocer de los mecanismos mediante los cuales los docentes ingresan a enseñar en las escuelas. Para el conjunto de América Latina, un poco más de un tercio de los docentes de primaria $(34,7 \%)$ ingresa a través de concurso público; un $30 \%$ lo hace por designación de alguna autoridad educativa; un 14,6\% es contratado directamente por el director/a de la escuela o centro educativo; un $6 \%$ es contratado por la propia comunidad escolar; y un porcentaje similar, por los dueños de los centros escolares (Tabla 7). En todo caso, ello presenta una enorme disparidad entre países. Así, mientras que el $84,3 \%$ de los docentes de primaria costarricenses accede mediante concurso público, en Nicaragua, lo hace menos de un $1 \%$. Llama la atención el caso de México, donde el $23 \%$ de los docentes han ingresado al cargo, producto de una decisión (atribución) del gremio o sindicato docente. El mayor peso de los dueños de centros escolares en la elección de los maestros refleja, también, la composición pública privada de los sistemas escolares.

La mirada para la situación del Perú muestra que un 38\% de los docentes son seleccionados a través de concursos públicos. Un 19\% de ellos son designados en el cargo por las autoridades; un $9 \%$ por el director/a de la escuela y un $11 \%$ por los propietarios de los centros educativos. Solo un $2 \%$ están en esos cargos por decisión de la comunidad educativa. Sería interesante profundizar en qué tipo de escuela o contexto los docentes pueden ser designados directamente, ya sea por las autoridades políticas o educativas, o por el propio director de las escuelas (Tabla 7). Es decir, dentro del contexto de una enorme variabilidad entre países, la situación de Perú es cercana a la situación media de América Latina. 
Tabla 7

Forma de acceso de los docentes de primaria en América Latina. Distribución en función de su forma de acceso

\begin{tabular}{lcccccc}
\hline & $\begin{array}{c}\text { Por } \\
\text { concurso } \\
\text { público }\end{array}$ & $\begin{array}{c}\text { Por } \\
\text { elección de } \\
\text { comunidad } \\
\text { escolar }\end{array}$ & $\begin{array}{c}\text { Por } \\
\text { designación } \\
\text { del director }\end{array}$ & $\begin{array}{c}\text { Por } \\
\text { designación } \\
\text { de las } \\
\text { autoridades }\end{array}$ & $\begin{array}{c}\text { Por } \\
\text { decisión de } \\
\text { propietarios }\end{array}$ & $\begin{array}{c}\text { Por } \\
\text { decisión } \\
\text { sindical }\end{array}$ \\
\hline Argentina & 42,29 & 1,24 & 25,12 & 21,64 & 4,73 & 0,00 \\
Brasil & 51,64 & 0,00 & 5,29 & 10,08 & 13,10 & 0,25 \\
Colombia & 23,00 & 0,26 & 17,31 & 41,09 & 11,37 & 0,00 \\
Costa Rica & 84,29 & 0,71 & 4,29 & 7,14 & 0,71 & 0,00 \\
Cuba & 6,57 & 0,00 & 7,46 & 84,48 & 0,30 & 0,00 \\
Chile & 21,43 & 0,34 & 12,93 & 34,35 & 25,85 & 0,00 \\
Ecuador & 21,74 & 1,93 & 14,98 & 51,21 & 4,83 & 0,48 \\
El Salvador & 24,90 & 31,13 & 8,17 & 26,07 & 1,95 & 0,00 \\
Guatemala & 35,34 & 21,55 & 6,47 & 24,14 & 6,47 & 0,00 \\
México & 13,66 & 0,98 & 11,71 & 38,54 & 4,88 & 23,41 \\
Nicaragua & 0,87 & 6,49 & 36,36 & 48,48 & 1,30 & 1,30 \\
Panamá & 73,90 & 1,61 & 8,84 & 6,43 & 5,62 & 0,00 \\
Paraguay & 32,10 & 20,16 & 24,28 & 12,35 & 2,06 & 0,00 \\
\hline Perú & 38,06 & 2,02 & 9,31 & 19,03 & 10,93 & 0,40 \\
\hline Rep. & 5,59 & 5,59 & 28,67 & 51,05 & 1,40 & 2,80 \\
Dominicana & & & & & & 1,36 \\
Uruguay & 78,98 & 0,34 & 12,20 & 1,69 & 6,05 & 1,81 \\
\hline Promedio & 34,65 & 5,90 & 14,59 & 29,86 & & 0,34 \\
\hline
\end{tabular}

Fuente: Elaboración propia a partir de los datos del Serce

Un 78\% de los docentes de América Latina, independientemente de la forma en que accede al cargo, cuenta con un contrato laboral por tiempo indefinido; mientras que un $18,6 \%$ solo dispone de contratos anuales que pueden ser renovables (Tabla 8). Estas condiciones claramente refieren a condiciones de estabilidad laboral, lo cual afecta aspectos sensibles y relevantes para la realidad personal y familiar de estos profesionales.

La situación de los docentes peruanos de primaria en este aspecto sí muestra diferencias con los países del entorno. Un 70,7\% de los mismos cuenta con un contrato laboral indefinido. Esto supone condiciones de precariedad e inestabilidad laboral para un $30 \%$ de quienes enseñan en el nivel de primaria en ese país (Tabla 8). 
Claramente, el contar con un empleo que asegure ingresos mensuales y estables en el tiempo favorece una actitud positiva frente al trabajo desarrollado y al ambiente en el cual se realiza. Por lo tanto, es posible empezar a atisbar en esta condición alguna causa de su malestar. Este es un elemento a mejorar por las administraciones educativas si se quiere mejorar la docencia en el Perú.

Tabla 8

Distribución de los docentes de primaria en América Latina en función del tipo de contrato

\begin{tabular}{lccc}
\hline & $\begin{array}{c}\text { Por tiempo } \\
\text { indefinido }\end{array}$ & $\begin{array}{c}\text { A plazo de un año con } \\
\text { posibilidades de seguir }\end{array}$ & $\begin{array}{c}\text { A plazo menor de un } \\
\text { año (suplencias, etc.) }\end{array}$ \\
\hline Argentina & 70,68 & 14,99 & 15,24 \\
Brasil & 69,92 & 27,57 & 2,51 \\
Colombia & 59,28 & 35,57 & 5,15 \\
Costa Rica & 79,14 & 17,99 & 2,88 \\
Cuba & 94,93 & 5,07 & 0,00 \\
Chile & 78,69 & 15,41 & 5,90 \\
Ecuador & 76,33 & 21,26 & 2,42 \\
El Salvador & 65,25 & 31,66 & 3,09 \\
Guatemala & 61,97 & 37,18 & 0,85 \\
México & 86,73 & 10,43 & 2,84 \\
Nicaragua & 87,82 & 10,08 & 2,10 \\
Panamá & 86,45 & 11,95 & 1,59 \\
Paraguay & 95,85 & 4,15 & 0,00 \\
\hline Perú & 70,68 & 26,51 & 2,81 \\
\hline Rep. Dominicana & 88,28 & 10,34 & 1,38 \\
Uruguay & 75,68 & 17,57 & 6,76 \\
\hline Promedio & 77,98 & 18,61 & 3,47 \\
\hline
\end{tabular}

Fuente: Elaboración propia, a partir de los datos del Serce

Es importante destacar que el $26,4 \%$ de los docentes combina la enseñanza en la escuela donde fue encuestado con otro trabajo remunerado. Este porcentaje se eleva de manera importante entre quienes enseñan en escuelas de gestión privada (Tabla 9). Las cifras son especialmente preocupantes en Brasil, México y Argentina, donde el $54,9 \%, 44,1 \%$ y $39,5 \%$, respectivamente, cuenta con otro trabajo. Cuba y Panamá, por el contrario, muestran los menores porcentajes, con un $4,2 \%$ y un $10 \%$ del total de sus docentes. 
En, aproximadamente, la totalidad de los países, el porcentaje de quienes se desempeñan en más de un trabajo es mayor entre los docentes de escuelas privadas.

Por su parte, los análisis para Perú señalan que un $24,1 \%$ de docentes combina la enseñanza con algún otro trabajo remunerado. Este indicador llega al 30,5\% en los profesores de escuelas privadas. Habría que anotar que estos datos, a pesar de que se encuentran ligeramente por debajo del promedio de los países de la región, muestran un reto a superar en estos próximos años.

Tabla 9

Porcentaje de docentes de primaria en América Latina con otro trabajo (total y por tipo de escuela)

\begin{tabular}{lcccc}
\hline & Total & Público/ Urbano & Privado/ Urbano & Rural \\
\hline Argentina & 39,52 & 40,00 & 44,04 & 30,30 \\
Brasil & 54,86 & 55,26 & 55,42 & 51,92 \\
Colombia & 20,97 & 12,09 & 32,14 & 24,74 \\
Costa Rica & 19,86 & 14,67 & 11,11 & 28,07 \\
Cuba & 4,18 & 4,69 & & 2,53 \\
Chile & 15,61 & 14,19 & 17,31 & 16,36 \\
Ecuador & 32,06 & 31,11 & 52,50 & 22,78 \\
El Salvador & 14,62 & 10,40 & 37,93 & 13,21 \\
Guatemala & 37,55 & 39,18 & 54,84 & 31,19 \\
México & 44,08 & 51,38 & 51,61 & 29,58 \\
Nicaragua & 24,79 & 28,89 & 32,50 & 11,11 \\
Panamá & 9,96 & 13,82 & 16,22 & 2,20 \\
Paraguay & 20,88 & 18,75 & 35,48 & 18,85 \\
\hline Perú & 24,06 & 24,16 & 30,51 & 17,24 \\
\hline Rep. Dominicana & 20,69 & 28,99 & 20,00 & 8,70 \\
Uruguay & 38,26 & 36,22 & 60,42 & 25,93 \\
\hline Promedio & 26,37 & 26,49 & 36,80 & 20,92 \\
\hline
\end{tabular}

Fuente: Elaboración propia, a partir de los datos del Serce

No es menor ni trivial que los docentes se desempeñen en más de un trabajo (incluso enseñando en una segunda escuela o turno nocturno). En esos casos, se ve afectado el tiempo disponible y necesario para la preparación de la enseñanza, así como el trabajo con otros docentes. Al igual que res- 
pecto del tipo de contrato, la situación de desdoblarse para rendir en más de un trabajo puede ser un factor que afecte la motivación e interés que tienen los profesores por la enseñanza, la escuela y los estudiantes.

\section{Distribución del tiempo}

Directamente ligado a las condiciones laborales, se encuentra la dedicación horaria de los docentes a su trabajo y el reparto de dicho tiempo. Para el conjunto de América Latina, los docentes dedican un promedio de 29,1 horas de trabajo a sus funciones como docente. Esta cifra varía de las 44,9 horas de Cuba a las 22,4 de Argentina. El Perú se encuentra en una situación intermedia, con 29,3 horas a la semana.

Desglosados los datos en función del tipo de escuela, se encuentra que los docentes que más horas trabajan son los que desarrollan sus funciones en escuelas rurales (30.1), seguido de los que lo hacen en escuelas privadas $(28,7)$ y, por último, en escuelas públicas urbanas $(28,5)$. Esta distribución, sin embargo, no se cumple para Perú, donde la diferencia entre las tres es mínima (29,4 en escuelas públicas urbanas; 29,1 en escuelas privadas; y 29,2 en escuelas rurales). 
Tabla 10

Promedio de horas de dedicación semanal a la escuela de los docentes de primaria en América Latina (total y por tipo de escuela)

\begin{tabular}{lcccc}
\hline & Total & Público Urbano & Privado Urbano & Rural \\
\hline Argentina & 22,41 & 22,56 & 20,47 & 25,13 \\
Brasil & 25,40 & 24,71 & 26,85 & 26,67 \\
Colombia & 30,09 & 29,70 & 32,06 & 28,99 \\
Costa Rica & 32,72 & 31,93 & 31,78 & 33,91 \\
Cuba & 44,90 & 45,29 &. & 43,62 \\
Chile & 36,58 & 35,61 & 37,15 & 38,20 \\
Ecuador & 27,30 & 27,16 & 26,40 & 27,92 \\
El Salvador & 31,77 & 28,78 & 33,17 & 34,93 \\
Guatemala & 24,50 & 24,01 & 27,55 & 24,07 \\
México & 25,51 & 23,79 & 32,19 & 25,16 \\
Nicaragua & 27,58 & 27,68 & 26,63 & 27,94 \\
Panamá & 31,22 & 29,71 & 35,81 & 31,51 \\
Paraguay & 26,11 & 27,18 & 24,90 & 25,59 \\
\hline Perú & 29,32 & 29,44 & 29,13 & 29,18 \\
\hline Rep. Dominicana & 22,93 & 22,52 & 21,73 & 24,30 \\
Uruguay & 27,51 & 26,34 & 25,17 & 33,83 \\
\hline Promedio & 29,12 & 28,53 & 28,73 & 30,06 \\
\hline
\end{tabular}

Fuente: Elaboración propia, a partir de los datos del Serce

Debido a que se teme que estas puntuaciones promedio oculten una gran variabilidad en la carga horaria de los docentes, se analiza la distribución de los mismos en función de su carga horaria (Tabla 11). Así, se descubre una gran dispersión en la carga horaria de los docentes de primaria de América Latina. Efectivamente, un $22,2 \%$ labora 20 horas o menos; un $43,14 \%$, entre 21 a 30 horas; y un 34,65\% lo hace más de 30 horas a la semana. Caso extremo de dispersión es Paraguay, donde más de la mitad trabaja 20 horas o menos; y el 40,8, más de 31 horas.

En oposición, está Perú, caso extremo de poca dispersión, donde el $80,2 \%$ de los docentes trabaja entre 21 y 31 horas a la semana. 
Tabla 11

Distribución de los docentes de primaria de América Latina respecto al número de horas de dedicación semanal

\begin{tabular}{lcccccc}
\hline & $0-10$ & $11-20$ & $21-30$ & $31-40$ & $41-50$ & $51-60$ \\
\hline Argentina & 6,44 & 46,65 & 36,86 & 8,25 & 1,29 &, 52 \\
Brasil & 4,30 & 38,23 & 34,18 & 17,72 & 4,30 & 1,27 \\
Colombia & 3,80 & 4,35 & 59,78 & 23,91 & 7,61 &, 54 \\
Costa Rica & 9,93 & 4,96 & 25,53 & 37,59 & 20,57 & 1,42 \\
Cuba & 2,39 & 0,30 & 0,00 & 17,61 & 70,75 & 8,96 \\
Chile & 1,32 & 1,65 & 23,10 & 47,19 & 25,08 & 1,65 \\
Ecuador & 9,57 & 5,26 & 64,11 & 19,14 & 1,91 & 0,00 \\
El Salvador & 5,41 & 1,93 & 60,62 & 3,86 & 23,94 & 4,25 \\
Guatemala & 9,28 & 3,38 & 79,32 & 7,59 & 0,00 & 0,42 \\
México & 2,48 & 17,33 & 67,82 & 11,88 & 0,50 & 0,00 \\
Nicaragua & 11,95 &, 44 & 60,18 & 26,55 & 0,44 & 0,44 \\
Panamá & 3,59 & 1,35 & 46,19 & 47,09 & 1,35 & 0,45 \\
Paraguay & 14,29 & 37,96 & 6,94 & 37,96 & 1,63 & 1,22 \\
\hline Perú & 4,94 & 2,47 & 80,25 & 10,29 & 2,06 & 0,00 \\
\hline Rep. Dominicana & 17,48 & 29,37 & 30,77 & 17,48 & 4,20 & 0,70 \\
Uruguay & 2,73 & 49,15 & 15,36 & 26,62 & 3,75 & 2,39 \\
\hline Promedio & 6,87 & 15,30 & 43,19 & 22,55 & 10,59 & 1,51 \\
\hline
\end{tabular}

Fuente: Elaboración propia, a partir de los datos del Serce

Más interesante y revelador resulta el estudio de la distribución de los tiempo de los docentes en diferentes tareas: trabajar con los alumnos en clase, preparar las clases, reunirse con profesores o director, corregir tareas o trabajos, reunirse con padres, atender a estudiantes fuera del horario, tareas administrativas y otras. Los datos indican que Perú es, junto con Guatemala, el país cuyos docentes dedican más porcentaje de tiempo a la docencia directa en la clase: más del $50 \%$ de su tiempo está dedicada a esas funciones. Estas constituyen cifras superiores al promedio de los países de América Latina, igual a 42,2\% y, desde luego, muy alto en comparación con Brasil (un 30,0\%) o Colombia $(34,8 \%)$. Esa mayor dedicación a la docencia directa en aula tiene sus consecuencia en ser uno de los países que menos tiempo dedica para trabajar en equipo con sus colegas (solo un $5,2 \%$, frente al $7,2 \%$ de promedio) y a preparar las clases y corregir trabajos y exámenes (24,0\%), muy lejos de países como Argentina (33,8\% del tiempo) o Brasil $(30,1 \%)$. 
Tabla 12

Distribución del tiempo de los docentes de primaria en América Latina ${ }^{1}$

\begin{tabular}{|c|c|c|c|c|c|c|c|}
\hline & $\begin{array}{l}\text { Trabajar } \\
\text { con los } \\
\text { alumnos } \\
\text { en clase }\end{array}$ & $\begin{array}{c}\text { Preparar } \\
\text { las } \\
\text { clases }\end{array}$ & $\begin{array}{l}\text { Reunirse } \\
\text { con } \\
\text { profesores } \\
\text { o director }\end{array}$ & $\begin{array}{l}\text { Corregir } \\
\text { tareas o } \\
\text { trabajos }\end{array}$ & $\begin{array}{l}\text { Reunirse } \\
\text { con } \\
\text { padres }\end{array}$ & $\begin{array}{c}\text { Atender a } \\
\text { estudiantes } \\
\text { fuera del } \\
\text { horario }\end{array}$ & $\begin{array}{c}\text { Tareas } \\
\text { administrativas }\end{array}$ \\
\hline Argentina & 43,49 & 18,70 & 5,63 & 15,14 & 4,91 & 1,57 & 4,78 \\
\hline Brasil & 29,98 & 13,97 & 10,29 & 11,89 & 9,35 & 8,14 & 8,35 \\
\hline Colombia & 34,78 & 15,84 & 7,69 & 14,23 & 5,50 & 6,76 & 5,97 \\
\hline Costa Rica & 46,46 & 15,82 & 4,67 & 9,58 & 5,57 & 4,18 & 6,70 \\
\hline Cuba & 49,99 & 15,22 & 7,98 & 11,86 & 3,89 & 5,22 & 1,34 \\
\hline Chile & 49,85 & 11,22 & 7,73 & 10,04 & 4,98 & 3,67 & 6,24 \\
\hline Ecuador & 47,99 & 14,55 & 5,55 & 11,31 & 6,94 & 3,60 & 4,06 \\
\hline El Salvador & 46,83 & 18,30 & 4,70 & 9,07 & 5,41 & 4,98 & 5,13 \\
\hline Guatemala & 50,44 & 12,07 & 4,90 & 9,80 & 6,25 & 4,97 & 5,11 \\
\hline México & 48,87 & 12,62 & 5,03 & 9,98 & 4,84 & 4,95 & 7,25 \\
\hline Nicaragua & 34,52 & 19,68 & 7,31 & 10,41 & 7,05 & 6,18 & 7,12 \\
\hline Panamá & 44,81 & 16,55 & 4,50 & 11,56 & 4,66 & 5,14 & 6,29 \\
\hline Paraguay & 13,05 & 20,43 & 20,31 & 19,49 & 16,13 & 2,54 & 3,82 \\
\hline Perú & 50,17 & 14,95 & 5,15 & 9,01 & 4,61 & 4,45 & 5,10 \\
\hline $\begin{array}{l}\text { Rep. } \\
\text { Dominicana }\end{array}$ & 43,60 & 15,15 & 5,76 & 11,33 & 7,47 & 4,44 & 4,73 \\
\hline Uruguay & 40,67 & 15,25 & 8,34 & 12,18 & 4,83 & 4,73 & 6,35 \\
\hline $\begin{array}{l}\text { Promedio } \\
\text { países }\end{array}$ & 42,22 & 15,64 & 7,22 & 11,68 & 6,40 & 4,72 & 5,52 \\
\hline
\end{tabular}

Fuente: Elaboración propia, a partir de los datos del Serce

En la Figura 2, se observa con toda claridad la gran cantidad de tiempo que los docentes dedican a la enseñanza directa en el aula. De este modo, descuidan tareas como preparar las clases o trabajar en equipo con sus colegas.

1. La suma no alcanza la cifra cien, puesto que falta la dedicación a "otras" tareas. 


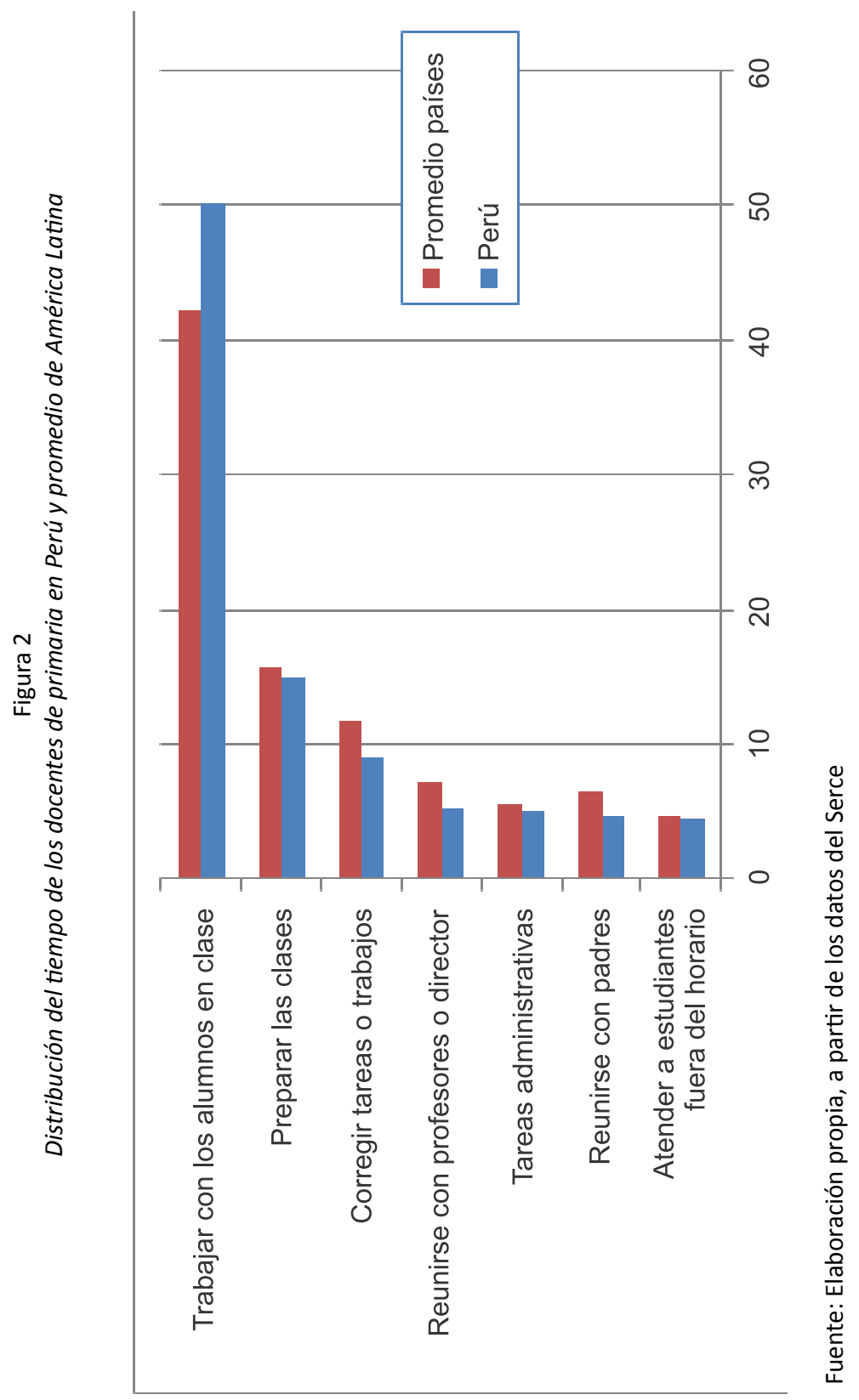


Esta distribución, sobrecargada de horas de clase y con poco tiempo para otras tareas, refleja un modelo de docencia y una exigencia a los maestros, así como maestros que pudieran estar en la base de su insatisfacción. Como luego se verá, la investigación es clara al señalar la relación entre el tiempo de preparación de las clases, del trabajo en equipo y el aprendizaje de los estudiantes.

\section{Satisfacción}

Se ha dejado para el final el análisis de las causas de las insatisfacciones de los docentes peruanos. Tal como se señaló en la introducción del texto, los docentes de primaria del Perú son, globalmente, los más insatisfechos con su trabajo de toda América Latina. La pregunta es "¿en qué?". Dedicaremos este último apartado a identificar los aspectos o condiciones que concitan ese malestar o desencanto entre los profesores en Perú.

Se recogieron datos de la satisfacción de los docentes respecto a quince aspectos diferentes ligados a su trabajo: su salario; su posibilidad de desarrollo profesional; la relación con sus colegas docentes, estudiantes, padres de familia y la comunidad; el apoyo recibido por parte de la dirección del centro educativo en temas pedagógicos, y, también, por parte de las autoridades educativas en temas pedagógicos; la libertad para realizar su trabajo; el apoyo de sus colegas; el respeto que le muestran los estudiantes en el aula; el reconocimiento del director por su trabajo; las oportunidades de trabajo en equipo con sus colegas; y su trabajo dentro del aula.

En todos estos aspectos, los docentes peruanos no solo están más descontentos que el promedio de América Latina, sino que es difícil encontrar un país que, en alguno de esos aspectos, esté más descontentos que ellos. Queda claro que es una situación de insatisfacción global, y no centrada en aspectos específicos, lo que supone una complejidad mayor.

En todo caso (Figura 3), los aspectos en los que reflejan su mayor descontento son con el apoyo de las autoridades educativas (no de la escuela) en temas pedagógicos y con su salario. En contraposición, el aspecto con el que más satisfechos están (aunque habría que decir "aquel con el que menos insatisfechos se encuentran") es con su relación con los padres de familia y con el respeto que muestran los estudiantes en el aula. En todo caso, son aspectos muy por debajo del promedio y, con alguna excepción, los más bajos de todos los países. 
Figura 3. Grado de satisfacción de los docentes peruanos y de América Latina con diferentes aspectos (escala de 1, nada satisfecho/a) a 4 (muy satisfecho/a)

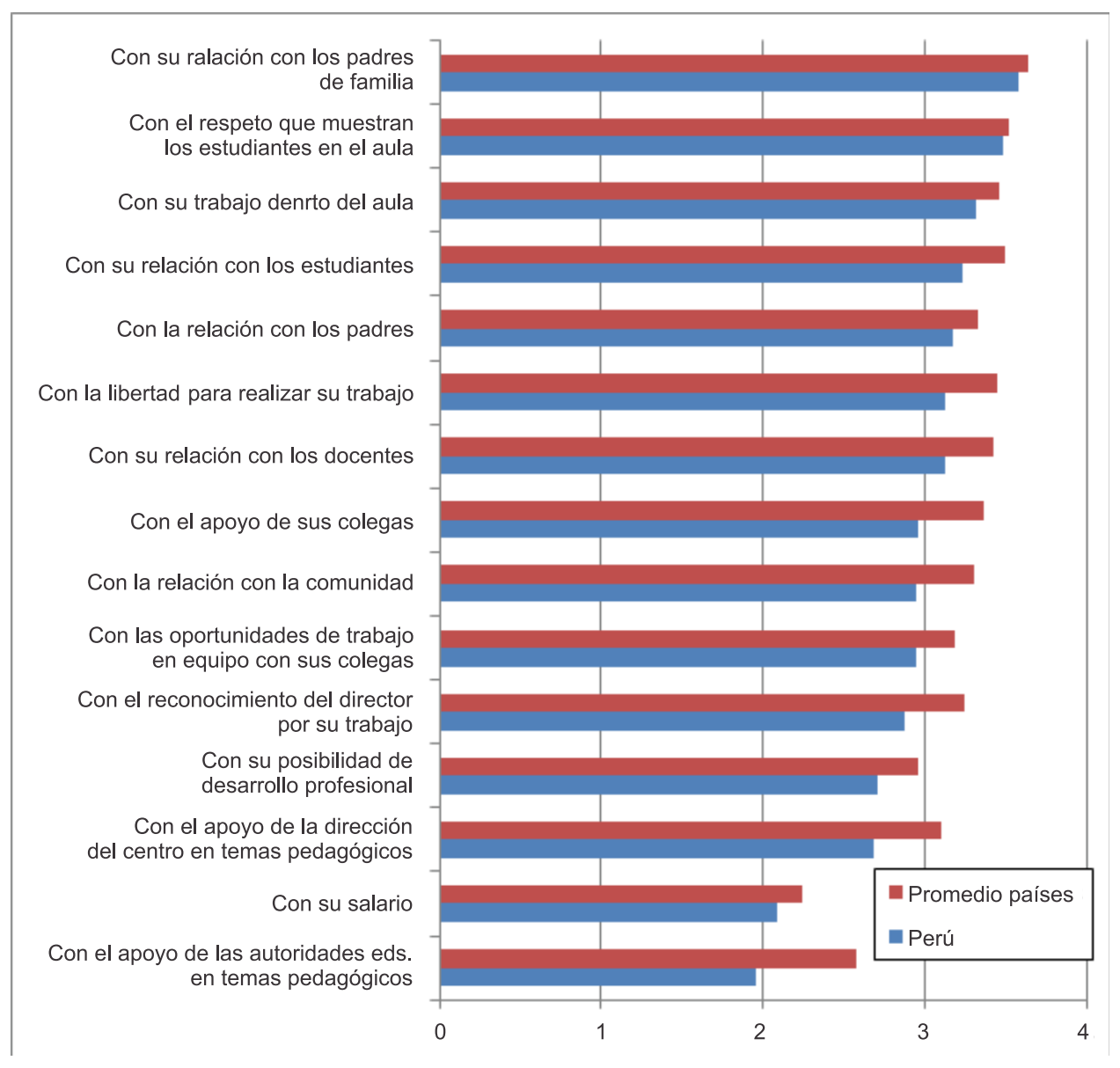

Fuente: Elaboración propia, a partir de los datos del Serce 
En los cuadros 13, 14 y 15, aparecen los datos de los 16 países analizados en los 15 aspectos estudiados.

\section{Cuadro 13}

Grado de satisfacción de los docentes de primaria en América Latina (escala de 1, nada satisfecho/a) a 4 (muy satisfecho/a) (1/3)

\begin{tabular}{|c|c|c|c|c|c|}
\hline & $\begin{array}{l}\text { Con su } \\
\text { salario }\end{array}$ & $\begin{array}{c}\text { Con su } \\
\text { posibilidad } \\
\text { de desarrollo } \\
\text { profesional }\end{array}$ & $\begin{array}{l}\text { Con su } \\
\text { relación con } \\
\text { los docentes }\end{array}$ & $\begin{array}{l}\text { Con su } \\
\text { relación con } \\
\text { los estudiantes }\end{array}$ & $\begin{array}{l}\text { Con su } \\
\text { relación con } \\
\text { los padres } \\
\text { de familia }\end{array}$ \\
\hline Argentina & 2,03 & 2,72 & 3,50 & 3,59 & 3,59 \\
\hline Brasil & 1,97 & 2,80 & 3,50 & 3,54 & 3,26 \\
\hline Colombia & 2,66 & 2,95 & 3,39 & 3,51 & 3,46 \\
\hline Costa Rica & 2,32 & 3,11 & 3,59 & 3,61 & 3,76 \\
\hline Cuba & 3,07 & 3,49 & 3,55 & 3,61 & 3,78 \\
\hline Chile & 2,37 & 2,83 & 3,43 & 3,55 & 3,66 \\
\hline Ecuador & 2,13 & 3,10 & 3,45 & 3,44 & 3,64 \\
\hline El Salvador & 2,30 & 2,98 & 3,50 & 3,59 & 3,78 \\
\hline Guatemala & 2,23 & 2,94 & 3,34 & 3,42 & 3,76 \\
\hline México & 2,30 & 2,90 & 3,29 & 3,35 & 3,59 \\
\hline Nicaragua & 1,81 & 2,89 & 3,39 & 3,41 & 3,71 \\
\hline Panamá & 2,48 & 3,06 & 3,43 & 3,43 & 3,65 \\
\hline Paraguay & 2,06 & 3,01 & 3,39 & 3,49 & 3,63 \\
\hline Perú & 2,09 & 2,71 & 3,12 & 3,23 & 3,58 \\
\hline $\begin{array}{l}\text { Rep. } \\
\text { Dominicana }\end{array}$ & 2,18 & 3,10 & 3,53 & 3,68 & 3,73 \\
\hline Uruguay & 1,84 & 2,70 & 3,39 & 3,54 & 3,68 \\
\hline $\begin{array}{l}\text { Promedio } \\
\text { países }\end{array}$ & 2,24 & 2,96 & 3,42 & 3,50 & 3,64 \\
\hline
\end{tabular}

Fuente: Elaboración propia, a partir de los datos del Serce 
Cuadro 14

Grado de satisfacción de los docentes de primaria en América Latina (escala de 1, nada satisfecho/a) a 4 (muy satisfecho/a) (2/3)

\begin{tabular}{|c|c|c|c|c|c|}
\hline & $\begin{array}{l}\text { Con la } \\
\text { relación } \\
\text { con los } \\
\text { padres }\end{array}$ & $\begin{array}{l}\text { Con el apoyo } \\
\text { recibido por } \\
\text { parte de la } \\
\text { dirección } \\
\text { del centro } \\
\text { educativo } \\
\text { en temas } \\
\text { pedagógicos }\end{array}$ & $\begin{array}{l}\text { Con el apoyo } \\
\text { recibido por } \\
\text { parte de las } \\
\text { autoridades } \\
\text { educativo } \\
\text { en temas } \\
\text { pedagógicos }\end{array}$ & $\begin{array}{l}\text { Con la } \\
\text { relación } \\
\text { con la } \\
\text { comunidad }\end{array}$ & $\begin{array}{l}\text { Con la } \\
\text { libertad para } \\
\text { realizar su } \\
\text { trabajo }\end{array}$ \\
\hline Argentina & 3,19 & 3,34 & 2,62 & 3,33 & 3,60 \\
\hline Brasil & 3,01 & 3,26 & 2,47 & 3,17 & 3,36 \\
\hline Colombia & 3,25 & 2,99 & 2,54 & 3,20 & 3,37 \\
\hline Costa Rica & 3,50 & 3,27 & 2,54 & 3,43 & 3,49 \\
\hline Cuba & 3,57 & 3,51 & 3,35 & 3,48 & 3,51 \\
\hline Chile & 3,38 & 3,16 & 2,54 & 3,33 & 3,44 \\
\hline Ecuador & 3,34 & 2,81 & 2,36 & 3,28 & 3,48 \\
\hline El Salvador & 3,50 & 3,23 & 2,78 & 3,48 & 3,51 \\
\hline Guatemala & 3,42 & 2,95 & 2,45 & 3,39 & 3,49 \\
\hline México & 3,21 & 2,84 & 2,53 & 3,16 & 3,46 \\
\hline Nicaragua & 3,34 & 3,01 & 2,36 & 3,32 & 3,50 \\
\hline Panamá & 3,36 & 3,15 & 2,63 & 3,20 & 3,41 \\
\hline Paraguay & 3,41 & 2,95 & 2,65 & 3,39 & 3,47 \\
\hline Perú & 3,17 & 2,68 & 1,95 & 2,95 & 3,12 \\
\hline $\begin{array}{l}\text { Rep. } \\
\text { Dominicana }\end{array}$ & 3,24 & 3,34 & 2,84 & 3,41 & 3,42 \\
\hline Uruguay & 3,32 & 3,15 & 2,60 & 3,27 & 3,49 \\
\hline $\begin{array}{l}\text { Promedio } \\
\text { países }\end{array}$ & 3,33 & 3,10 & 2,58 & 3,30 & 3,45 \\
\hline
\end{tabular}

Fuente: Elaboración propia, a partir de los datos del Serce 
Cuadro 15

Grado de satisfacción de los docentes de primaria en América Latina (escala de 1, nada satisfecho/a) a 4 (muy satisfecho/a) (3/3)

\begin{tabular}{|c|c|c|c|c|c|}
\hline & $\begin{array}{l}\text { Con el } \\
\text { apoyo } \\
\text { de sus } \\
\text { colegas }\end{array}$ & $\begin{array}{l}\text { Con el } \\
\text { respeto que le } \\
\text { muestran los } \\
\text { estudiantes } \\
\text { en el aula }\end{array}$ & $\begin{array}{l}\text { Con el } \\
\text { reconocimiento } \\
\text { del director por } \\
\text { su trabajo }\end{array}$ & $\begin{array}{c}\text { Con las } \\
\text { oportunidades } \\
\text { de trabajo en } \\
\text { equipo con sus } \\
\text { colegas }\end{array}$ & $\begin{array}{c}\text { Con su } \\
\text { trabajo } \\
\text { dentro } \\
\text { del aula }\end{array}$ \\
\hline Argentina & 3,54 & 3,46 & 3,37 & 3,18 & 3,42 \\
\hline Brasil & 3,37 & 3,13 & 3,29 & 3,15 & 3,18 \\
\hline Colombia & 3,30 & 3,41 & 3,19 & 3,25 & 3,40 \\
\hline Costa Rica & 3,51 & 3,55 & 3,59 & 3,34 & 3,64 \\
\hline Cuba & 3,53 & 3,72 & 3,48 & 3,44 & 3,60 \\
\hline Chile & 3,42 & 3,54 & 3,19 & 3,07 & 3,48 \\
\hline Ecuador & 3,30 & 3,61 & 3,29 & 3,20 & 3,49 \\
\hline El Salvador & 3,43 & 3,64 & 3,30 & 3,35 & 3,63 \\
\hline Guatemala & 3,27 & 3,65 & 3,19 & 3,17 & 3,60 \\
\hline México & 3,17 & 3,38 & 3,07 & 3,02 & 3,31 \\
\hline Nicaragua & 3,29 & 3,53 & 2,92 & 3,20 & 3,58 \\
\hline Panamá & 3,32 & 3,59 & 3,24 & 3,29 & 3,52 \\
\hline Paraguay & 3,38 & 3,51 & 3,24 & 3,21 & 3,44 \\
\hline Perú & 2,96 & 3,48 & 2,87 & 2,94 & 3,32 \\
\hline $\begin{array}{l}\text { Rep. } \\
\text { Dominicana }\end{array}$ & 3,52 & 3,55 & 3,26 & 3,24 & 3,37 \\
\hline Uruguay & 3,40 & 3,54 & 3,32 & 3,07 & 3,41 \\
\hline $\begin{array}{l}\text { Promedio } \\
\text { países }\end{array}$ & 3,36 & 3,52 & 3,24 & 3,19 & 3,46 \\
\hline
\end{tabular}

Fuente: Elaboración propia, a partir de los datos del Serce

Una última revisión nos lleva a mirar otro indicador de la satisfacción de los docentes: su deseo de cambiarse de escuela (Tabla 16). Resulta sorprendente encontrar que el Perú es el país con un mayor porcentaje de profesores que les gustaría ser reasignados de escuela, si pudieran. Esta cifra llega casi a la mitad del conjunto de docentes (49,2\%). Más impresionante es aún el mayoritario porcentaje de docentes rurales peruanos que se cambiarán y desean ser reasignados a otra escuela: $71,2 \%$.

Ello hace indispensable profundizar en estudios posteriores en las condiciones en que se desempeña la tarea docente en el contexto rural. El arraigo 
o sentido de pertenencia de un docente respecto de su escuela y su comunidad resultan claves para la motivación y el desafío de aportar al aprendizaje de los estudiantes y, por ende, actuar en consecuencia. Poco o nada se puede hacer desde acciones de apoyo para la innovación y mejora escolar si la mitad de los profesores se desea cambiar o, peor aún, si así lo desean siete de cada diez de quienes enseñan en las escuelas rurales de ese país.

Tabla 16

Porcentaje de docentes de primaria en América Latina que les gustaría ser reasignados (total y por tipo de escuela)

\begin{tabular}{lcccc}
\hline & Total & Público Urbano & Privado Urbano & Rural \\
\hline Argentina & 10,63 & 8,33 & 12,50 & 15,87 \\
Brasil & 7,42 & 8,08 & 1,20 & 14,58 \\
Colombia & 17,13 & 21,08 & 5,88 & 22,73 \\
Costa Rica & 27,54 & 21,92 & 11,11 & 37,50 \\
Cuba & 3,65 & 3,98 & & 2,56 \\
Chile & 14,48 & 8,57 & 17,89 & 23,64 \\
Ecuador & 34,67 & 14,12 & 33,33 & 58,67 \\
El Salvador & 25,59 & 12,10 & 28,57 & 41,18 \\
Guatemala & 27,95 & 26,67 & 9,68 & 34,26 \\
México & 18,27 & 14,81 & 3,23 & 30,43 \\
Nicaragua & 18,61 & 8,40 & 33,33 & 31,15 \\
Panamá & 38,27 & 24,79 & 14,29 & 64,84 \\
Paraguay & 18,60 & 15,05 & 16,13 & 22,03 \\
\hline Perú & 49,16 & 45,59 & 36,00 & 71,15 \\
\hline Rep. Dominicana & 21,99 & 14,93 & 37,93 & 22,22 \\
Uruguay & 21,58 & 25,13 & 6,38 & 22,22 \\
\hline Promedio & 22,22 & 17,10 & 17,83 & 32,19 \\
\hline
\end{tabular}

Fuente: Elaboración propia, a partir de los datos del Serce

\section{Discusión e implicaciones}

¿Por qué importa saber quiénes son los docentes que forman a los niños y las niñas en el Perú y en América Latina? ¿Por qué interesa saber qué hacen, qué los motiva o el porqué de su malestar profesional? Simple y sencillamente, 
porque allí se juega parte importante de la calidad educativa que todo sistema y escuela debe asegurar a sus estudiantes. En otras palabras, porque esa calidad, tan buscada y esquiva, encuentra sus límites y posibilidades en los atributos, capacidades, actitudes, motivación, prácticas y subjetividades de los educadores.

Seguimos en deuda con una parte importante de los niños y las niñas que asisten a la educación primaria en nuestra región. Seguimos insistentemente tratando de buscar pistas y alternativas que nos orienten respecto de cómo mejorar la enseñanza y el aprendizaje en tantas aulas y escuelas de nuestros sistemas. Así, hemos visto inundado el campo educativo de políticas y acciones de focalización y compensación, de alternativas y sistemas de evaluación de los aprendizajes y del desempeño profesional docente, de modelos de apoyo para la mejora sustentados en la eficacia y escuelas eficaces, de inclusión y disminución de la brechas digitales mediante la incorporación masiva de TIC en las escuelas, entre tantos otros. No es el propósito de este texto -ni de estas reflexiones- el comprender y argumentar las razones y factores que pudieran explicar lo poco avanzado desde todas esas iniciativas. El retrotraerlas al final de estas palabras responde a que toda la evidencia que de ellas emerge no hace sino ratificar la relevancia, centralidad y protagonismo del profesor para el mayor o menor éxito en el desafío compartido de lograr mejores, más significativos y estables aprendizajes en los estudiantes. Junto con los aspectos didácticos y disciplinarios, la planificación y organización de la enseñanza, la satisfacción, motivación, responsabilidad y compromiso que muestran estos formadores con la educación, las escuelas y sus comunidades se consolidan como factores relevantes para aquello que aprenden y logran los estudiantes. Sin embargo, hay que tener cuidado: saberlos relevantes y esenciales es del todo distinto de responsabilizarlos de la baja o insuficiente calidad educativa de los sistemas y en las escuelas. Lamentablemente, en muchas ocasiones, se les ha culpabilizado y ha mostrado como los grandes y exclusivos responsables. Nos preocupa pensar que esta permanente mirada crítica hacia los docentes haya terminado por quitarles la pasión y alegría por enseñar, por hacer de ellos un cuerpo profesional que encuentra más frustración que logros en lo que hace y muestra.

Este estudio completa y complementa el trabajo de Falus y Goldberg (2011) con datos del Serce, el cual supone también una continuidad a estudios como los de Emilio Tenti $(2003,2006,2007)$ desde el IIPE. Sin embargo, su aporte -además de focalizar su atención en los docentes peruanos-, se dirige en mayor medida al tema de las satisfacciones e insatisfacciones de los docentes y pretende buscar una explicación a la situación en Perú. 
Hemos querido detener la mirada en los docentes de escuelas primarias del Perú, justamente, porque son ellos quienes se muestran mayormente desmotivados con su tarea formadora y con el espacio institucional donde la realizan. No hay que olvidar que la investigación desarrollada tanto en América Latina como en el resto del mundo es clara en determinar la relación entre la satisfacción del docente con sus condiciones laborales, y su compromiso y el desempeño de sus estudiantes. Así, lo demuestran, entre otros, Quaglia, Marion y McIntire (1991), Dinham y Scott $(1998,2000)$, Stockard y Lehman (2004), Crossman y Harris (2006), Leithwood (2006), Berry, Smylie y Fuller (2008), y Liu y Ramsey (2008); o Murillo (2007) y Cornejo (2009) en el ámbito Latinoamericano. De esta forma, parece claro que no es posible mantener sistemas educativos de calidad, donde todos y cada uno de los estudiantes aprenda y se desarrolle, con docentes insatisfechos.

A partir de la discusión y reflexión en torno a la evidencia de los datos, esperamos aportar con ideas y alternativas que ayuden a mejorar la motivación, el compromiso y confianza de las profesoras y profesores. ¿Qué podemos entonces concluir con los datos y análisis realizados? Recorrámoslos y reflexionemos al respecto.

Interesante conocer que Perú es el país con la mayor proporción de hombres enseñando en sus escuelas de primaria. En efecto, cuatro de cada diez docentes en ese nivel son hombres. En contextos rurales, los hombres son más de la mitad. Este equilibrio entre hombres y mujeres frente a aulas rurales podría ser un aporte al intercambio y reflexión pedagógica al interior de las escuelas y al propio sistema.

Por su parte, los análisis por tramo de edad nos muestran que casi el $40 \%$ de los docentes de primaria son menores de 38 años y otro tanto tienen edades entre 39 y 48 años. Es decir, casi el $80 \%$ de quienes enseñan en el nivel de primaria del país tienen menos de 48 años. Esta condición es sin duda una gran ventaja para todo lo que supone actualización o formación en ejercicio para apoyar y enriquecer el trabajo pedagógico de estos profesionales. Desde la motivación, son tramos etarios en los que se busca y estima atractivo el seguir aprendiendo para un mejor desempeño y acreditarse en ello.

En el caso de los análisis que dan cuenta de los años de experiencia como docente y el tiempo promedio de permanencia en las escuelas se observa una mayor estabilidad entre quienes enseñan en las escuelas públicas y urbanas (algo más de nueve años) y bastante menor -aunque igualmente considerable-, entre quienes lo hacen en escuelas privadas (cinco años). En otras palabras y con los matices del caso, la rotación docente no es un asunto que se levante como uno de los problemas importantes para los maestros y, por ende, para el sistema. En ese sentido, no aparece como obvio o evidente que 
una inestabilidad o fragilidad laboral sea un factor que concentre el malestar y descontento de los profesores peruanos.

Detengámonos, ahora, en revisar si su insatisfacción radica en no contar con una adecuada formación inicial que pudiera frustrarlos al no sentirse preparados suficientemente para desarrollar con éxito y confianza las diversa tareas que supone la labor docente.

Los datos son contundentes. Casi el $90 \%$ de los maestros de primaria en Perú posee formación inicial finalizada como docentes. En el mundo rural, este porcentaje llega al $86 \%$. No obstante, las buenas cifras -es importante asumir que un $10 \%$ de quienes están enseñando en primaria-no han recibido o no han completado una formación especializada para tal función.

Si profundizamos en el tipo de formación recibida (independientemente de si la concluyó o no), se observan aspectos interesantes. Por ejemplo, un $49 \%$ de los profesores se ha formado como docente en espacios no universitarios, mientras que un $37 \%$ tiene una formación pedagógica universitaria. Un 6\% del conjunto de profesores de primaria ha accedido a estudios de especialización de postgrado. En el otro extremo, preocupa el 7,4\% de actuales docentes que solo han alcanzado estudios de nivel secundario.

Al leer estos datos en busca de una explicación del global descanto de estos maestros, nos percatamos de que no parece ser que se encuentre en estos aspectos (al menos no visto en sí mismo y en comparación al resto de docentes de América Latina). Sin embargo, debemos ser claros, también, en señalar que no necesariamente el contar con una formación inicial de más o menos años -universitaria o técnica-, asegura mejores condiciones, competencias profesionales o actitudes para desarrollar en mejores condiciones la docencia. Ello sin duda depende de la calidad y relevancia de tal formación: de su sintonía, pertinencia y contextualización a la realidad, y desafíos que los maestros encontrarán al enseñar en las distintas escuelas del sistema.

Las autoridades educativas del Perú tienen acá una gran oportunidad y un desafío. En primer lugar, ello se centra en incrementar las ofertas y condiciones para que los profesores puedan acceder a estudios de postgrado y de perfeccionamiento en ejercicio. Simultáneamente, se encuentra el desafío de hacer de ellos espacios de formación más pertinente y aterrizada a la cotidianeidad de las escuelas y sus poblaciones escolares. Esta estrategia, junto a aspectos disciplinarios, debe trabajar también y centralmente la confianza, motivación y expectativas de estos docentes. Estas posibilidades y oportunidades resultan de mayor relevancia para quienes laboran es escuelas rurales, quienes por las distancias y condiciones cuentan con menos opciones para acceder a espacios formativos. Dentro de este contexto, estudiar alternativas 
de apoyos o becas para mejorar la formación de los maestros rurales será algo muy bien recibido y valorado por ellos.

No hay indicios que nos lleven a pensar que la forma mediante la cual accedieron al cargo de profesor pudiera ser un factor importante en el desencanto de estos docentes; al menos no si no es evidente una arbitrariedad en las asignaciones de cargos. Por encima de ello, estarán siempre las condiciones y el ambiente del centro o institución donde se realiza la tarea y el trabajo pedagógico. No obstante, siempre será mejor una total transparencia en la forma mediante la cual se puede acceder a un puesto de trabajo, que sentir que hay arbitrariedad en dicho acceso.

Unido a lo anterior está la situación laboral con que cuentan los maestros y maestras peruanos. Situación que muestra algunas diferencias con los países del entorno. Un 70,7\% de los profesores de primaria del Perú cuenta con un contrato laboral indefinido. Esto supone condiciones de precariedad e inestabilidad laboral para el $30 \%$ de aquellos que enseñan en el nivel de primaria en este país. Ello contrasta con América Latina, cuya cifra es cercana al $20 \%$ y es menor aún en otros países de la región. Este factor es, a todas luces, sensible y relevante para la realidad personal y familiar de estos profesionales. Se convierte, así, rápidamente en un factor de preocupación, insatisfacción y malestar para quienes se ven amenazados en su fuente laboral por no contar con un contrato que los resguarde.

Avanzar, en tal sentido, aparece también como un desafío para los legisladores, autoridades nacionales y, especialmente, para los administradores. Cuidar a los docentes y resguardar su condición y derechos de trabajador debería repercutir en una actitud positiva frente al trabajo desarrollado y con el lugar en el cual se realiza y, por ende, en una mejor docencia.

Independientemente de si las cifras de los docentes que combina la enseñanza con algún otro trabajo remunerado son mayores en Perú que en otros países de la región, lo que acá importa es reiterar que tal condición atenta directamente con la necesidad de preparar responsablemente la enseñanza, y limita el intercambio y el trabajo con otros docentes. Esto, unido al menor tiempo libre y las responsabilidades en más de un espacio laboral, fácilmente puede llegar a ser la razón de la falta de motivación e interés de los profesores. En este caso, el desafío es disminuir ese $24 \%$ de maestros peruanos que tienen un segundo trabajo remunerado.

Al detener la mirada en la carga semanal que supone la docencia para los docentes de primaria en Perú, nos encontramos con que una gran mayoría (80\%) trabaja entre 21 y 31 horas en dicho período. Este aspecto parece ser bastante adecuado de acuerdo a la región e incluso respecto de otras profesiones. Lo interesante es que más del $50 \%$ de ese tiempo lo dedican al trabajo 
directo con alumnos en el aula. Esta cifra supera con mucho el promedio regional (42\%) y, largamente, a lo que ocurre en otros países.

Creemos no equivocarnos al identificar en este aspecto parte importante de la insatisfacción o descontento de los docentes peruanos. Las demandas y desafíos para un mejor trabajo con los estudiantes necesitan de profesores con tiempo sin aula, para poder preparar y organizar la enseñanza. Ello, además, implica momentos frecuentes para discutir lo hecho e innovado con otros docentes, para luego reflexionar sobre la propia práctica y actuar en consecuencia. Todos ellos son aspectos que se ven ratificados también en este estudio, desde los menores tiempos que destinan a esas y otras actividades los docentes en Perú.

Cuando el tiempo disponible se consume en el trabajo de aula, difícilmente, se puede avanzar y mejorar en lo que allí ocurre. Sumado a lo anterior, está el hecho del mayor cansancio que provoca tener que concentrar el trabajo en un tipo de acción, sin la necesaria combinación con otras actividades y responsabilidades. Estas son las que permiten mayor compromiso y motivación al momento de enfrentar esos procesos de enseñanza y aprendizaje en el aula. En la demanda histórica de los docentes de todos los países de la región, aparece una y otra vez no solo disminuir el número de alumnos por aula, sino reducir el número de horas frente al aula. Ello se constituye como una condición para poder preparar mejor, reflexionar sobre lo hecho y logrado, a fin de mejorar permanentemente. Desde esa perspectiva, es del todo posible que esta sobrecarga del trabajo en aula concite parte importante del descanto o insatisfacción de los docentes de este país. En efecto, esta distribución que recarga a los docentes de horas directas frente al aula y deja escaso tiempo para otras tareas en la escuela da cuenta de un modelo de docencia que exige y no entrega condiciones para hacerlo bien. Sin duda, es probable que allí radique parte importante del malestar del que informan estos profesionales. Otro enorme desafío para las autoridades y los administradores -una posible acción tendiente a mejorar esta condición- es aumentar las horas contratadas, a condición de liberar parte de la jornada para el trabajo explícito de preparación y trabajo en equipo, que redunde en un mejor desarrollo del trabajo en sala de clases. El resultado de ello sería más tiempo para pensar y reflexionar, así como mejores condiciones para implementar la enseñanza y el aprendizaje.

Es interesante recordar que muchas investigaciones -en su mayoría norteamericanas y europeas- aportan claras evidencias de que la distribución del tiempo (sobrecarga de trabajo, aceleración con la que los docentes han de realizar las tareas, el aumento en el número de tareas asignadas a su jornada laboral o la "presión por el tiempo") está directamente relacionada 
con la insatisfacción y el malestar docente (por ejemplo, Hargreaves, 2003; Schaufeli y Bakker,2004; Peeters y Rutte, 2005; Lindqvist y Nordänger, 2006; Kokkinos, 2007; Skaalvik y Skaalvik, 2008, 2009). Sin embargo, también, hay numerosos estudios que encuentran la relación entre el tiempo dedicado a la preparación y planificación de las clases, y el desempeño de los estudiantes (tal es el caso de Mortimore et al., 1988; Gall, 1989; Waxman y Walberg, 1999; Walbergy Paik, 2000; Murillo, 2007).

Pese a que esta revisión podría explicar este descanto global frente a la tarea docente -lo cual se refleja en casi todos los aspectos que ello implica-, no termina por dar a entender el altísimo porcentaje de profesores peruanos que, sin dudarlo, se cambiaría de escuela. La mitad, a nivel global, y 7 de cada 10 en escuelas rurales así lo harían. Frente a ello, habría que preguntarse, si la insatisfacción es contra aspectos más bien estructurales, del sistema y sus regulaciones, ¿cómo se explica este profundo y masivo malestar respecto de la institución donde se trabaja?

Esta evidencia no hace más que alertarnos respecto de qué pasa en los centros educativos que concita tal reacción adversa, o qué es aquello que estos profesionales desean y no encuentran en dichos centros. En coherencia con los análisis y resultados comentados anteriormente, pensamos que este deseo de cambio da cuenta de un reclamo transversal por sentirse más acompañados, reconocidos y respaldados en su tarea pedagógica. A pesar de lo aprendido y avanzado, la enseñanza y el aprendizaje siguen siendo vistos y asumidos como exclusiva responsabilidad del docente, que es quien deberá arreglárselas como pueda y sepa para ejercer bien su labor e independientemente de las condiciones, recursos o apoyos que encuentre en la escuela o centro educativo en el que enseña.

El caso extremo de los docentes rurales en Perú hace urgente profundizar en estudios posteriores en las condiciones en que desempeñan la tarea docente en el contexto rural. Reiteramos que el arraigo o sentido de pertenencia de un profesor/a respecto de su escuela y su comunidad resultan claves para la motivación y el desafío que implica lograr la apropiación de aprendizajes relevantes y pertinentes en los alumnos. Ello, también, involucra comprometerlos con el presente y futuro de cada niño y niña, dando lo mejor de sí cotidianamente.

Parece ser que tanta crítica hacia el trabajo de los docentes ha terminado consiguiendo que estos reaccionen con frustración e insatisfacción hacia casi todo lo que les toca hacer. Es tiempo de empezar a reconocer su labor y no solo a mostrar o dejar en evidencia aquello que no logran o dónde aparecen más débiles. Hacer de la escuela, de la dirección y la comunidad reales e incondicionales apoyos al trabajo del maestro no implica no mostrar lo que 
está mal o débil. Será importante que los administradores generen recursos y condiciones que permitan hacer del apoyo, el reconocimiento y la colaboración al trabajo docente, una práctica permanente e institucionalizada. Se debe favorecer el que los maestros se sientan acompañados y respaldados en lo que hacen y que encuentren allí, también, la posibilidad y capacidad de mejorar aquello más débil, inadecuado o insuficiente de su acción pedagógica y desempeño profesional.

Es preciso resaltar que solo es posible tener sistemas educativos de calidad con maestros motivados, contentos, reconocidos y recompensados en su tarea. Poco o nada se puede esperar en aquellos casos donde los profesores asumen su rol formador desde la desidia, la frustración o el anhelo de dejar esa escuela lo antes posible. El sistema peruano, así como tantos otros (casi la totalidad) en esta región, requiere sostenerse en docentes que, más allá de su formación y preparación profesional, se apasionen con la tarea educativa, disfruten del saber y hacer de sus alumnos, sean empáticos con la situación y realidad familiar de ellos, creativos para despertar en cada niño/a y sus familias, el amor y valoración por la educación. Es necesario tener maestros y maestras que encuentren en sus escuelas el apoyo y contención -en tanto individuos y profesionales- para poder, desde allí, construir y reconstruir cotidianamente la razón y sentido del enseñar y aprender.

El elemento clave, por tanto, es la necesidad imperiosa de que las administraciones educativas confíen con claridad y determinación en profesores y profesoras; confíen en su buen hacer, en su profesionalismo; confíen apoyándolos en sus dificultades, apartándoles posibilidades para su desarrollo personal y profesional, remunerándolos adecuadamente y dándoles unas condiciones de trabajo dignas. Solo así se conseguirá que la sociedad confíe en sus docentes; y solo así se estará en la senda de un sistema educativo que contribuya a una sociedad más justa, inclusiva y democrática. 


\section{Referencias}

Berry, B., Smylie, M. y Fuller, E. (2008). Understanding teacher working conditions: A review and look to the future. Hillsborough. NC: Center for Teaching Quality.

Cornejo, R. (2009). Condiciones de trabajo y bienestar/malestar docente en profesores de enseñanza media en Santiago de Chile. Educação \& Sociedade, 30(107), 409-426.

Creemers, B.M.P. (1994). The effective classroom. Londres: Cassell.

Crossman, A. y Harris, P. (2006). Job satisfaction of secondary school teachers. Educational Management Administration \& Leadership, 34, 29-46.

Dinham, S. y Scott, C. (1998). A Three Domain Model of Teacher and School Executive Satisfaction. Journal of Educational Administration, 36(4), 362378.

(2000). Moving Into The Third, Outer Domain Of Teacher Satisfaction. Journal of Educational Administration, 38(4), pp. 379-396.

Falus, L. y Goldberg, M. (2011). Perfil de los docentes en América Latina. Buenos Aires: Siteal.

Gall, M. (1989). Synthesis of research on teacher's questioning. En L. W. Anderson (Ed.). The effective teacher: study guide and readings (pp.250289). Nueva York: Random House.

Hargreaves, A. (2003). Teaching in the knowledge society: Education in the age of insecurity. Milton Keynes: Open University Press.

Huyaert, S. H. (1998). Time is of the essence: Learning in schools. Boston: Allyn and Bacon.

Kokkinos, C. M. (2007). Job stressors, personality and burnout in primary school teachers. British Journal of Educational Psychology, 77, 229-243.

Leithwood, K. (2006). Teacher Working Conditions That Matter: Evidence for Change. Toronto, Ontario: Elementary Teachers' Federation of Ontario.

Lindqvist, P., y Nordänger, U. K. (2006). Who dares to disconnect in the age of uncertainty? Teachers' recesses and "off-the-clock" work. Teachers and Teaching: Theory and Practice, 12, 623-637.

Liu, X. S. y Ramsey, J. (2008). Teachers' job satisfaction: Analyses of the teacher follow-up survey in the United States for 2000-2001. Teaching and Teacher Education, 24, 1173-1184.

Laboratorio Latinoamericano de Evaluación de la Calidad de la Educación (2008). Los aprendizajes de los estudiantes de América Latina y el Caribe. Primer Reporte SERCE. Santiago de Chile: Orealc/Unesco. 
Mortimore, P., Sammons, P., Stoll, L., Lewis, D. y Ecob, R. (1988). School matters: The junior years. Somerset: Open Books.

Murillo, F.J. (2005). La investigación sobre eficacia escolar. Barcelona: Octaedro.

(Coord.) (2007). Investigación Iberoamericana sobre Eficacia Escolar. Bogotá: Convenio Andrés Bello.

Murillo, F.J., Martínez Garrido, C. y Hernández-Castilla, R. (2011). Decálogo para una enseñanza eficaz. REICE. Revista Iberoamericana sobre Calidad, Eficacia y Cambio en Educación, 9(1), 6-27.

Peeters, M. A. G. y Rutte, C. G. (2005). Time management behaviour as a moderator for the job demand-control interaction. Journal of Occupational Health Psychology, 10, 64-75

Quaglia, R., Marion, S.F. y McIntire, W.G. (1991). The relationship of teacher satisfaction to perceptions of school organization, teacher empowerment, work conditions, and community status. Education, 112, 206-217.

Román, M. (2008). Investigación Latinoamericana sobre Enseñanza Eficaz, ILEE. En Unesco. Eficacia escolar y factores asociados en América Latina y el Caribe (pp. 209-225). Santiago de Chile: Unesco.

Sammons, P. (2007). School Effectiveness and Equity: Making connections. Reading: CFBT.

Schaufeli, W. B. y Bakker, A. D. B. (2004). Job demands, job resources, and their relationship with burnout and engagement: a multi-sample study. Journal of Organizational Behavior, 25, 293-315.

Skaalvik, E. M. y Skaalvik, S. (2008). Teacher self-efficacy: Conceptual analysis and relations with teacher burnout and perceived school context. En $\mathrm{H}$. W. Marsh, R. G. Craven y D. M. McInerney (Eds.). Self-processes, learning, and enabling human potential (pp. 223-247). Connecticut: Information Age Publishing.

(2009). Does school context matter? Relations with teacher burnout and job satisfaction. Teaching and Teacher Education, 25(3), 518-524.

Stockard, J. y Lehman, M.B. (2004). Influences on the satisfaction and retention of first-year teachers: The importance of effective school management. Educational Administration Quarterly, 40(5), 742-771.

Tenti, E. (2003). Algunas dimensiones de la profesionalización de los docentes. Representaciones y temas de la agenda política. Buenos Aires: IIPE.

(Comp.) (2006). El oficio de docente, trabajo y profesión en el Siglo XXI. Buenos Aires: Siglo XXI Editores. 
(2007). La condición docente. Análisis comparado de la Argentina, Brasil, Perú y Uruguay. Buenos Aires: Siglo XXI Editores.

Walberg, J.H. y Paik, D.J. (2000). Effective educational practices. Ginebra: IBE/ Unesco.

Waxman, H.C. y Walberg, H.J. (1999). New directions for teaching practice and research. Berkeley, CA: McCutchan Publishing. 